\title{
Molecular Characterisation of Isolates Belonging to Candida Parapsilosis Species Complex and Determination of Their Antifungal Resistance Profiles
}

\author{
Caner Yuruyen ${ }^{1 *}$, Ahmet Mert Kuskucu ${ }^{2}$, Kenan Midilli $^{2}$, Zayre Erturan ${ }^{3}$, Gulden Celik ${ }^{4}$ \\ ${ }^{1}$ Dr. Siyami Ersek Chest Heart and Vascular Surgery Training and Research Hospital, Medical Microbiology Laboratory, Istanbul, Turkey \\ ${ }^{2}$ Istanbul University, Cerrahpasa Medical Faculty, Medical Microbiology Department, Istanbul, Turkey \\ ${ }^{3}$ Istanbul University, Istanbul Medical Faculty, Medical Microbiology Department, Istanbul, Turkey \\ ${ }^{4}$ Bahçeșehir University, Medical Faculty, Medical Microbiology Department, Istanbul, Turkey
}

DOI: $10.36348 /$ sjpm.2019.v04i11.011

| Received: 14.11.2019| Accepted: 21.11.2019| Published: 28.11.2019

*Corresponding author: Caner Yürüyen

\section{Abstract}

Introduction: This study aimed to differentiate among the species belonging to the Candida parapsilosis complex, which is one of the leading causes of systemic mycoses through molecular characterisation and to determine their antifungal resistance pattern. Material and Methods: Ninety-five C. parapsilosis complex isolates identified using two yeast identification systems, BioMérieux ID 32C and Vitek $2^{\mathrm{TM}}$ with YST card, were included in this study. Molecular characterisation was achieved by polymerase chain reaction-restriction fragment length polymorphism analysis of the secondary alcohol dehydrogenase gene. Isolates that could not be identified using this technique were identified by internal transcribed spacer (ITS) sequencing. Antifungal susceptibility was evaluated using the Vitek $2^{\mathrm{TM}}$ AST-YS06 card. Results: Out of the 95 isolates, 94 were identified as C. parapsilosis sensu stricto, and only one isolate was identified as C. orthopsilosis; the latter result was achieved using ITS sequencing. C. orthopsilosis was susceptible against all tested antifungal agents. Among the $\mathrm{C}$. parapsilosis sensu stricto isolates, three were found to be resistant: one to amphotericin B, two to fluconazole of which one showed intermediate resistance to voriconazole. Discussion: Isolation rates of $\mathrm{C}$. orthopsilosis and $\mathrm{C}$. metapsilosis in this study show that they are rare species. It was not possible to compare resistance among these three species due to very low isolation rates of $\mathrm{C}$. orthopsilosis and $\mathrm{C}$. metapsilosis. The use of molecular identification tests for these species in routine laboratory settings remains controversial. Nevertheless, their isolation rates and antifungal resistance patterns are important from the epidemiological viewpoint.

Keywords: Candida parapsilosis; Candida orthopsilosis; Candida metapsilosis; restriction fragment length polymorphism; antifungal susceptibility.

Copyright @ 2019: This is an open-access article distributed under the terms of the Creative Commons Attribution license which permits unrestricted use, distribution, and reproduction in any medium for non-commercial use (NonCommercial, or CC-BY-NC) provided the original author and sources are credited.

\section{INTRODUCTION}

The number of opportunistic fungal organisms has been increasing each year, but Candida still remains the most common disease-causing genus. Among the Candida species, non-albicans Candida species have increased in number. Worldwide, Candida parapsilosis complex has become the most commonly isolated nonalbicans species from blood cultures [1-4]. It is not a coincidence that the isolation rate of $C$. parapsilosis complex has increased. This commensal species can easily spread in hospital environments when necessary infection control measures are not taken. It can multiply in total parenteral nutrition formulas as well as form biofilms on catheters and other invasive equipment; therefore, it can easily infect susceptible patients [1].
Even though the genetic diversity of $C$. parapsilosis had been known before, until 2005, it was characterised as a species complex which included three subspecies that could not be differentiated using phenotypic methods. In 2005, Tavanti et al. demonstrated that these three subspecies are sufficiently dissimilar to be named as three different species: $C$. parapsilosis sensu stricto, $C$. metapsilosis and $C$. orthopsilosis [5]. Since then, many studies have investigated if there are any differences in the virulence and antifungal susceptibility patterns among these new species $[6,7]$.

The aim of this study is to estimate the distribution rates of species belonging to the $C$. parapsilosis complex prevalent in Turkey and to determine the probable differences in their antifungal 
susceptibility patterns, which can affect treatment. This study provides new epidemiological information which can be useful in a prophylactic and empirical antifungal treatment guide.

\section{Experimental Section}

\section{Selection of Strains}

This study includes 95 isolates of C. parapsilosis complex identified using the two yeast identification systems, BioMérieux ID 32C and Vitek $2^{\mathrm{TM}}$ with YST card. These isolates were found by screening various clinical samples obtained between the years 2009 and 2015 (Table-1). Strains were stored at $-80^{\circ} \mathrm{C}$ in the brain heart infusion broth containing $3 \%$ glycerol. They were subcultured onto Sabouraud dextrose agar (SDA) and CHROMagar ${ }^{\mathrm{TM}}$ Candida agar plates and incubated at $37^{\circ} \mathrm{C}$ for $24 \mathrm{~h}$.

Table-1: Distribution of sample types from which $C$. parapsilosis complex strains were isolated

\begin{tabular}{|c|c|}
\hline Sample Type & C. parapsilosis complex (n) \\
\hline Blood & 33 \\
\hline Urine & 19 \\
\hline Sputum & 17 \\
\hline Oral swab & 8 \\
\hline Abscess & 4 \\
\hline Conjunctival swab & 3 \\
\hline Tracheal Aspirate & 2 \\
\hline Skin and Nail & 2 \\
\hline Catheters & 2 \\
\hline Rectal swab & 2 \\
\hline Deep throat swab & 1 \\
\hline Peritoneal fluid & 1 \\
\hline Unknown & 1 \\
\hline
\end{tabular}

C. parapsilosis ATCC 22019, C. metapsilosis ATCC 96144, C. orthopsilosis ATCC 96139, $C$. metapsilosis CECT 13010 and C. orthopsilosis CECT 13011 were included in the study as reference strains.

\section{Polymerase Chain Reaction (PCR)}

The single-colony PCR method was chosen due to its ease of application and low cost [8]. In this method, a single yeast colony can be added directly into the amplification mix of PCR.

The secondary alcohol dehydrogenase $(S A D H)$ gene region, which is shared by the three subspecies of the $C$. parapsilosis complex, was amplified by PCR. The following forward and reverse primers, respectively, as defined by Tavanti et al., were used: 5GTTGATGCTGTTGGATTGT-3 and 5CAATGCCAAATCTCCCAA-3 [5]. The amplification mix is represented in the Table- 2 . The amplification steps in the Biorad T100 thermal cycler were as follows: one denaturation cycle for $4 \mathrm{~min}$ at $95^{\circ} \mathrm{C}$ followed by 40 cycles of denaturation at $95^{\circ} \mathrm{C}$ for 0.5 min, annealing at $50^{\circ} \mathrm{C}$ for $1 \mathrm{~min}$, elongation at $72^{\circ} \mathrm{C}$ for $1.5 \mathrm{~min}$ and a final extension step of $5 \mathrm{~min}$ at $72^{\circ} \mathrm{C}$.

Table-2: Amplification mix

\begin{tabular}{|l|c|}
\hline Component & Amount \\
\hline Taq DNA Polymerase $(5 \mathrm{U} / \mu \mathrm{L})$ & $0.125 \mu \mathrm{L}$ \\
\hline $10 \mathrm{X}$ buffer solution $\left(\mathrm{NH}_{4}\right)_{2} \mathrm{SO}_{4}$ (within the polymerase kit) & $2.5 \mu \mathrm{L}$ \\
\hline $25 \mathrm{mM} \mathrm{MgCl}{ }_{2}$ & $1.5 \mu \mathrm{L}$ \\
\hline $10 \mathrm{mM}$ dNTP & $0.5 \mu \mathrm{L}$ \\
\hline $25 \mu \mathrm{M}$ forward primer & $0.5 \mu \mathrm{L}$ \\
\hline $25 \mu \mathrm{M}$ reverse primer & $0.5 \mu \mathrm{L}$ \\
\hline Template DNA (yeast suspension) & $2 \mu \mathrm{L}$ \\
\hline Water & $17.375 \mu \mathrm{L}$ \\
\hline Total & $25 \mu \mathrm{L}$ \\
\hline
\end{tabular}

\section{Restriction and Electrophoresis}

A PCR product measuring 716 base pairs (bp) in length was identified electrophoretically using an agarose gel concentration of $1.7 \%$. For restriction enzyme digestion, a mixture consisting of $5 \mu \mathrm{L}$ PCR product, $8 \mu \mathrm{L}$ water, $0.5 \mu \mathrm{L}$ BanI restriction enzyme (New England Biolabs) and $1.5 \mu \mathrm{L}$ buffer solution (provided with the enzyme kit) was incubated at $37^{\circ} \mathrm{C}$ for $1 \mathrm{~h}$. Restriction products were separated from each other electrophoretically in a $1.7 \%$ agarose gel. C. parapsilosis sensu stricto yielded two pieces measuring $521 \mathrm{bp}$ and $196 \mathrm{bp}$, while C. metapsilosis yielded four pieces measuring $370 \mathrm{bp}, 188 \mathrm{bp}, 93 \mathrm{bp}$ and $60 \mathrm{bp}$. C. orthopsilosis did not split at all.

\section{Antifungal Susceptibility Testing Antifungal susceptibility testing was performed using the Vitek $2^{\text {TM }}$ AST-YS06}


(BioMérieux) card according to the manufacturer recommendations. MIC ranges of the antifungal agents present in the Vitek $2^{\mathrm{TM}}$ AST-06 card are shown in Table-3. Results were evaluated after incubation for 24 $\mathrm{h}$ at $35^{\circ} \mathrm{C}$. Antifungal susceptibility results were separately evaluated using EUCAST and CLSI criteria.

Table-3: Vitek 2 ${ }^{\mathrm{TM}}$ AST-YSO6 card content

\begin{tabular}{|l|c|c|}
\hline Antifungal agent & \multicolumn{2}{|c|}{ MIC interval* } \\
\hline & S & R \\
\hline & $\leq$ & $\geq$ \\
\hline Amphotericin B & 0.25 & 16 \\
\hline Caspofungin & 0.25 & 4 \\
\hline Fluconazole & 1 & 64 \\
\hline Flucytosine & 1 & 64 \\
\hline Voriconazole & 0.12 & 8 \\
\hline \multicolumn{2}{|c|}{$*$ All values in $\mu \mathrm{g} / \mathrm{mL}$}
\end{tabular}

\section{Sequencing and Phylogenetic Tree}

One strain could not be identified using the polymerase chain reaction-restriction fragment length polymorphism (PCR-RFLP) method. Internal transcribed spacer (ITS) regions of these strains were amplified using PCR as specified in the literature [9]. PCR product was purified using the High Pure PCR Product Purification kit (Roche, Mannheim, Germany). After the purification step, bidirectional DNA sequence analysis was performed using the dye terminator method by employing the Applied Biosystems Big Dye v1.1 (Applied Biosystems, Foster City, USA) kit. Acquired data was evaluated using Applied Biosystems Sequencing Analysis v5.3.1 software.

\section{RESULTS}

Identification results of C. parapsilosis complex strains Only one strain was identified as $C$. orthopsilosis by sequencing because PCR-RFLP experiment failed to identify it, while the rest of the 94 strains were identified as $C$. parapsilosis sensu stricto.

Antifungal susceptibility results of C. parapsilosis complex strains

All of the strains were susceptible to caspofungin according to CLSI M60 breakpoints. In EUCAST version 9.0, interpretation of caspofungin was combined with interpretations of micafungin and anidulafungin. Because Vitek 2 ${ }^{\mathrm{TM}}$ AST-06 card lacks these antifungal agents, it was not possible to make an interpretation for caspofungin according to EUCAST criteria. Because there were no established breakpoints for flucytosine in CLSI M60 and EUCAST version 9.0 antifungal breakpoint tables, it was not possible to make an interpretation.

Two strains were resistant against fluconazole according to both EUCAST version 9.0 and CLSI M60 criteria. One of them showed intermediate resistance against voriconazole. One strain was found to be resistant against amphotericin B according to EUCAST version 9.0 criteria. CLSI antifungal susceptibility criteria did not include any breakpoints for amphotericin B; therefore, it was not possible to make an interpretation. MIC values and sample types of resistant strains can be seen in Table- 4 .

Table-4: MIC values in $\mu \mathrm{g} / \mathrm{mL}$ and sample types of resistant strains

\begin{tabular}{|c|c|c|c|c|c|c|}
\hline $\begin{array}{c}\text { Strain } \\
\text { number }\end{array}$ & $\begin{array}{c}\text { Sample } \\
\text { Type }\end{array}$ & $\begin{array}{c}\text { Amphotericin B } \\
(\boldsymbol{\mu} \mathbf{g} / \mathbf{m L})\end{array}$ & $\begin{array}{c}\text { Caspofungin } \\
(\boldsymbol{\mu} \mathbf{g} / \mathbf{m L})\end{array}$ & $\begin{array}{c}\text { Fluconazole } \\
(\boldsymbol{\mu} \mathbf{g} / \mathbf{m L})\end{array}$ & $\begin{array}{c}\text { Flucytosine } \\
(\boldsymbol{\mu g} / \mathbf{m L})\end{array}$ & $\begin{array}{c}\text { Voriconazole } \\
(\boldsymbol{\mu} \mathbf{g} / \mathbf{m L})\end{array}$ \\
\hline 8 & Blood & $\mathbf{4}$ & 0.5 & 2 & $\leq 1$ & $\leq 0.12$ \\
\hline 69 & Blood & $\leq 0.25$ & 0.5 & $\mathbf{3 2}$ & $\leq 1$ & $\mathbf{0 . 2 5}$ \\
\hline 70 & Urine & $\leq 0.25$ & 0.5 & $\mathbf{8}$ & $\leq 1$ & $\leq 0.12$ \\
\hline
\end{tabular}

The $C$. orthopsilosis strain was found to be susceptible to all the antifungal agents tested. The MIC values of amphotericin $\mathrm{B}$, caspofungin, fluconazole, flucytosine and voriconazole were measured as $\leq 0.25$ $\mu \mathrm{g} / \mathrm{mL}, \leq 0.25 \mu \mathrm{g} / \mathrm{mL}, \leq 1 \mu \mathrm{g} / \mathrm{mL}, \leq 1 \mu \mathrm{g} / \mathrm{mL}$ and $\leq 0.12$ $\mu \mathrm{g} / \mathrm{mL}$, respectively.

\section{Sequencing Results}

The strain number 2, whose PCR result was unclear, was identified as C. orthopsilosis. Using the basic local alignment search tool (BLAST), this strain number 2 was recorded to have a $100 \%$ match with one strain and $99 \%$ match with many strains.

\section{DISCUSSION}

Importance of the correct identification at species level has increased as the rate of infections caused by yeasts other than $C$. albicans increased. Species-level identification gives preliminary information about antifungal susceptibility which makes the need for accurate identification crucial. Identification and distribution of $C$. parapsilosis complex species were performed using different methods. Isolation rates of $C$. parapsilosis sensu stricto, C. orthopsilosis and $C$. metapsilosis range between $71 \%-100 \%, 0 \%-26 \%$ and $0 \%-28 \%$, respectively, in different studies [5, 10, 11]. Lockhart et al., determined the species distribution of 1929 clinical $C$. parapsilosis complex isolates collected worldwide and found that $92 \%$ of them were C. parapsilosis sensu stricto, $6 \%$ were $C$. orthopsilosis and $2 \%$ were $C$. metapsilosis [7]. Two studies from Turkey found similar rates with $C$. parapsilosis sensu stricto being the most common species having an isolation rate of $>90 \%[12,13]$.

PCR-RFLP was the chosen method for the present study because it is a simple, inexpensive and relatively rapid method. This method like all other similar methods has certain limitations. Optimisation of conventional PCR requires considerable time and manual work during the experiment, which increases the possibility of errors. This method has lower sensitivity than the sequencing technique. In the present study, it was not possible to obtain the PCR product of 
a strain which was identified as $C$. orthopsilosis using ITS sequencing. $C$. orthopsilosis is known to be genetically diverse, thereby having polymorphisms at target locations $[14,15]$. It is possible that primers were not able to bind to their target and thus generate a product.

Antifungal susceptibility experiments on $C$. parapsilosis complex were focused more toward echinocandin-group antifungal agents. The reason for this is that wild-type $C$. parapsilosis complex species have reduced susceptibility to echinocandins [16, 17]. In our study, all of the strains were susceptible to caspofungin.

Another important class of antifungal agents used in the treatment of $C$. parapsilosis infections is triazoles. Voriconazole and posaconazole are effective against all the three subspecies of the complex [18]. Results of fluconazole are more equivocal. Several studies have reported that $C$. orthopsilosis and $C$. metapsilosis have higher fluconazole MIC values than C. parapsilosis sensu stricto and may display resistance against this antifungal $[2,8,19,20]$. In our study, two isolates were resistant against fluconazole and one of them also showed resistance against voriconazole.

In studies which investigated the susceptibility of $C$. parapsilosis complex to amphotericin B, MIC values of $C$. parapsilosis sensu stricto strains were found to be higher than those of $C$. orthopsilosis and $C$. metapsilosis strains, and some studies have reported the resistance among $C$. parapsilosis sensu stricto strains to this drug [7, 18-21]. In our study, only one isolate showed resistance against amphotericin B.

The chosen antifungal susceptibility method for this study was the use of Vitek $2^{\text {TM }}$ AST-YS06 (BioMérieux) cards. Vitek $2^{\mathrm{TM}}$ system was preferred because it is both rapid and accurate with high reproducibility. MIC is determined objectively in this method which is another advantage. Studies comparing this method with broth microdilution reference method for $C$. parapsilosis complex isolates showed very high rates of essential and categorical agreement and concluded that this method can be used as an alternative to the broth microdilution method [22-26].

\section{CONCLUSION}

Separate identification of C. parapsilosis complex species using molecular methods is not suitable in routine laboratory settings. One contributing reason is that the combined isolation rates of $\mathrm{C}$. orthopsilosis and C. metapsilosis are $<10 \%$ on an average. Another more important reason is that the difference in antifungal susceptibility of C. orthopsilosis and C. metapsilosis strains compared with C. parapsilosis sensu stricto strain remains controversial. Nonetheless, isolation rates and antifungal susceptibility results of these three species should be closed monitored for determining changes in epidemiological patterns.

\section{REFERENCES}

1. Trofa, D., Gácser, A., \& Nosanchuk, J. D. (2008). Candida parapsilosis, an emerging fungal pathogen. Clinical microbiology reviews, 21(4), 606-625.

2. van Asbeck, E., Clemons, K. V., Martinez, M., Tong, A. J., \& Stevens, D. A. (2008). Significant differences in drug susceptibility among species in the Candida parapsilosis group. Diagnostic microbiology and infectious disease, 62(1), 106109.

3. van Asbeck, E. C., Clemons, K. V., \& Stevens, D. A. (2009). Candida parapsilosis: a review of its epidemiology, pathogenesis, clinical aspects, typing and antimicrobial susceptibility. Critical reviews in microbiology, 35(4), 283-309.

4. Pfaller, M. A., Diekema, D. J., Gibbs, D. L., Newell, V. A., Ng, K. P., Colombo, A., ... \& Wadula, J. (2008). Geographic and temporal trends in isolation and antifungal susceptibility of Candida parapsilosis: a global assessment from the ARTEMIS DISK Antifungal Surveillance Program, 2001 to 2005. Journal of clinical microbiology, 46(3), 842-849.

5. Tavanti, A., Davidson, A. D., Gow, N. A., Maiden, M. C., \& Odds, F. C. (2005). Candida orthopsilosis and Candida metapsilosis spp. nov. to replace Candida parapsilosis groups II and III. Journal of clinical microbiology, 43(1), 284 292.

6. Chen, Y. C., Lin, Y. H., Chen, K. W., Lii, J., Teng, H. J., \& Li, S. Y. (2010). Molecular epidemiology and antifungal susceptibility of Candida parapsilosis sensu stricto, Candida orthopsilosis, and Candida metapsilosis in Taiwan. Diagnostic microbiology and infectious disease, 68(3), 284-292.

7. Lockhart, S. R., Messer, S. A., Pfaller, M. A., \& Diekema, D. J. (2008). Geographic distribution and antifungal susceptibility of the newly described species Candida orthopsilosis and Candida metapsilosis in comparison to the closely related species Candida parapsilosis. Journal of clinical microbiology, 46(8), 2659-2664.

8. Mirhendi, H., Diba, K., Rezaei, A., Jalalizand, N., Hosseinpur, L., \& Khodadadi, H. (2007). Colony PCR is a rapid and sensitive method for DNA amplification in yeasts. Iranian Journal of Public Health, 40-44.

9. White, T. J., Bruns, T., Lee, S. J. W. T., \& Taylor, J. (1990). Amplification and direct sequencing of fungal ribosomal RNA genes for phylogenetics. PCR protocols: a guide to methods and applications, 18(1), 315-322.

10. Ge, Y. P., Boekhout, T., Zhan, P., Lu, G. X., Shen, Y. N., Li, M., ... \& Liu, W. D. (2012). Characterization of the Candida parapsilosis 
complex in East China: species distribution differs among cities. Medical mycology, 50(1), 56-66.

11. Thierry, G., Morio, F., Le Pape, P., Gay-Andrieu, F., Barre, O., \& Miegeville, M. (2011). Prevalence de Candida parapsilosis, C. orthopsilosis et de C. metapsilosis au sein des candidemies au CHU de Nantes et profil de sensibilite aux echinocandines par la methode E-test ${ }^{\circledR}$ : etude retrospective de cinq ans (2004-2009). Pathologie Biologie, 59(1), 52-56.

12. Güler, N. C., Tosun, İ., Bayramoğlu, G., Buruk, K., \& Aydin, F. (2011). Klinik Örneklerden İzole Edilen Candida parapsilosis Kompleks Türlerinin (C. parapsilosis sensu stricto, C. metapsilosis ve C. orthopsilosis) Genotipik Olarak Tanımlanması ve Dağılımlarının

Belirlenmesi. Mikrobiyol Bul, 45(4), 723-728.

13. Tosun, I., Akyuz, Z., Guler, N. C., Gulmez, D., Bayramoglu, G., Kaklikkaya, N., ... \& Aydin, F. (2013). Distribution, virulence attributes and antifungal susceptibility patterns of Candida parapsilosis complex strains isolated from clinical samples. Medical mycology, 51(5), 483-492.

14. Tavanti, A., Hensgens, L. A., Ghelardi, E., Campa, M., \& Senesi, S. (2007). Genotyping of Candida orthopsilosis clinical isolates by amplification fragment length polymorphism reveals genetic diversity among independent isolates and strain maintenance within patients. Journal of clinical microbiology, 45(5), 1455-1462.

15. Merseguel, K. B., Nishikaku, A. S., Rodrigues, A. M., Padovan, A. C., e Ferreira, R. C., de Azevedo Melo, A. S., ... \& Colombo, A. L. (2015). Genetic diversity of medically important and emerging Candida species causing invasive infection. $B M C$ infectious diseases, 15(1), 57.

16. Földi, R., Kovács, R., Gesztelyi, R., Kardos, G., Berényi, R., Juhász, B., ... \& Majoros, L. (2012). Comparison of in vitro and vivo efficacy of caspofungin against Candida parapsilosis, C. orthopsilosis, C. metapsilosis and C. albicans. Mycopathologia, 174(4), 311-318.

17. Spreghini, E., Orlando, F., Tavanti, A., Senesi, S., Giannini, D., Manso, E., \& Barchiesi, F. (2012). In vitro and in vivo effects of echinocandins against Candida parapsilosis sensu stricto, Candida orthopsilosis and Candida metapsilosis. Journal of Antimicrobial Chemotherapy, 67(9), 2195-2202.

18. Szabó, Z., Szilágyi, J., Tavanti, A., Kardos, G., Rozgonyi, F., Bayegan, S., \& Majoros, L. (2009). In vitro efficacy of 5 antifungal agents against Candida parapsilosis, Candida orthopsilosis, and Candida metapsilosis as determined by time-kill methodology. Diagnostic microbiology and infectious disease, 64(3), 283-288.

19. Gomez-Lopez, A., Alastruey-Izquierdo, A., Rodriguez, D., Almirante, B., Pahissa, A.,
Rodriguez-Tudela, J. L., \& Cuenca-Estrella, M. (2008). Prevalence and susceptibility profile of Candida metapsilosis and Candida orthopsilosis: results from population-based surveillance of candidemia in Spain. Antimicrobial agents and chemotherapy, 52(4), 1506-1509.

20. Cantón, E., Pemán, J., Quindós, G., Eraso, E., Miranda-Zapico, I., Álvarez, M., ... \& Yagüe, G. (2011). Prospective multicenter study of the epidemiology, molecular identification, and antifungal susceptibility of Candida parapsilosis, Candida orthopsilosis, and Candida metapsilosis isolated from patients with candidemia. Antimicrobial agents and chemotherapy, 55(12), 5590-5596.

21. Silva, A. P., Miranda, I. M., Lisboa, C., Pina-Vaz, C., \& Rodrigues, A. G. (2009). Prevalence, distribution, and antifungal susceptibility profiles of Candida parapsilosis, C. orthopsilosis, and C. metapsilosis in a tertiary care hospital. Journal of clinical microbiology, 47(8), 2392-2397.

22. Pfaller, M. A., Diekema, D. J., Procop, G. W., \& Rinaldi, M. G. (2007). Multicenter comparison of the VITEK 2 yeast susceptibility test with the CLSI broth microdilution reference method for testing fluconazole against Candida spp. Journal of clinical microbiology, 45(3), 796-802.

23. Pfaller, M. A., Diekema, D. J., Procop, G. W., \& Rinaldi, M. G. (2007). Multicenter comparison of the VITEK 2 antifungal susceptibility test with the CLSI broth microdilution reference method for testing amphotericin B, flucytosine, and voriconazole against Candida spp. Journal of clinical microbiology, 45(11), 3522-3528.

24. Pfaller, M. A., Diekema, D. J., Procop, G. W., \& Rinaldi, M. G. (2013). Comparison of the Vitek 2 yeast susceptibility system with CLSI microdilution for antifungal susceptibility testing of fluconazole and voriconazole against Candida spp., using new clinical breakpoints and epidemiological cutoff values. Diagnostic microbiology and infectious disease, 77(1), 37-40.

25. Peterson, J. F., Pfaller, M. A., Diekema, D. J., Rinaldi, M. G., Riebe, K. M., \& Ledeboer, N. A. (2011). Multicenter comparison of the Vitek 2 antifungal susceptibility test with the CLSI broth microdilution reference method for testing caspofungin, micafungin, and posaconazole against Candida spp. Journal of clinical microbiology, 49(5), 1765-1771.

26. Bourgeois, N., Dehandschoewercker, L., Bertout, S., Bousquet, P. J., Rispail, P., \& Lachaud, L. (2010). Antifungal susceptibility of 205 Candida spp. isolated primarily during invasive candidiasis and comparison of the Vitek 2 system with the CLSI broth microdilution and Etest methods. Journal of clinical microbiology, 48(1), 154-161. 